\title{
SOME OBSERVED LOW-LEVEL AIR TRAJECTORIES OVER LOS ANGELES, CALIFORNIA
}

\author{
GEORGE C. HOLZWORTH 1 \\ U.S: Weather Bureau, Los Angeles, Calif. \\ ERWIN K. KAUPER \\ os Angeles County Air Pollution Control District, Los Angeles, Calif. \\ THEODORE B. SMITH \\ Meteorology Research Inc., Altadena, Calif. \\ [Manuscript received September 25, 1962; revised May 14, 1963
}

\begin{abstract}
Small constant-volume balloons, floating within $1700 \mathrm{ft}$. of the surface, were visually tracked over metropolitan Los Angeles by teams in automobiles. The trajectories and supporting data that were obtained are discussed, as are observing techniques and some operational difficulties.
\end{abstract}

\section{INTRODUCTION}

Previous studies of low-level air flow in the Los Angeles region $[1,2]$ have involved the use of surface-based wind observations. Since it may be postulated that the lowlevel flow aloft may be different from that near the surface, some economical method has been sought that could provide information on the flow aloft. Fluorescent tracer tests by Neiburger [3] only partially confirmed trajectories derived from surface wind reports.

The technique of determining air flow by tracking small constant-volume, tetrahedron-shaped balloons (tetroons) by means of radar has been described by Angell and Pack $[4,5,6]$. Over land in southern California this technique was not successful for low-level tetroon flights because of excessive ground clutter. Resort was made, therefore, to visually tracking tetroons as suggested by Professor W. L. Gates of the University of California at Los Angeles. The tetroon flights conducted in this test series were to serve two purposes: (1) to determine the feasibility of tracking tetroons visually by means of mobile observer teams, and (2) to provide trajectories at some short distance above the ground for comparison with trajectories based on surface wind observations.

\section{METHOD OF OBSERVATION}

Visual positioning of tetroons was carried out by observer teams in automobiles. Three such teams took part in this experiment, one each from the U.S. Weather Bu-

\footnotetext{
1 This portion of the work supported by the U.S. Public Health Service.
}

reau, from Meteorology Research, Inc., Altadena, Calif., and from the Los Angeles County Air Pollution Control District. Tetroon positions were established by use of the grid furnished by the street layouts of the Los Angeles metropolitan area. The observer car was driven so as to be as near the tetroon as possible. As an aid in determining the tetroon's position in space, one tracking team used a monocular eye piece with 1- and 2-degree angular diameter circles to estimate the apparent tetroon size (angular width). This information together with the actual tetroon size was used to obtain the slant range. The elevation angle of the tetroon (obtained with a clinometer) plus the slant range determined the elevation and horizontal range.

Constant-volume balloon operations are based upon the principle that the density of the balloon system remains constant and the balloon tends to float along a level in the atmosphere at which the air density equals that of the balloon system. Previous experience with tetroons has shown, however, that they follow vertical air motions to a considerable degree [5]. The tetroons used in the experiments measured $3.5 \mathrm{ft}$. from corner to corner. Their volume was $0.32 \mathrm{~m}^{3}$ and they were ballasted to a free lift of $3.5 \mathrm{gm}$. They were super-pressured to $25 \mathrm{mb}$. at the surface to insure a constant volume.

\section{OBSERVED TRAJECTORIES}

The tracking experiment was conducted on July 27, 1961, a rather typical summer day in Los Angeles. Thin stratus began to form over downtown Los Angeles at 

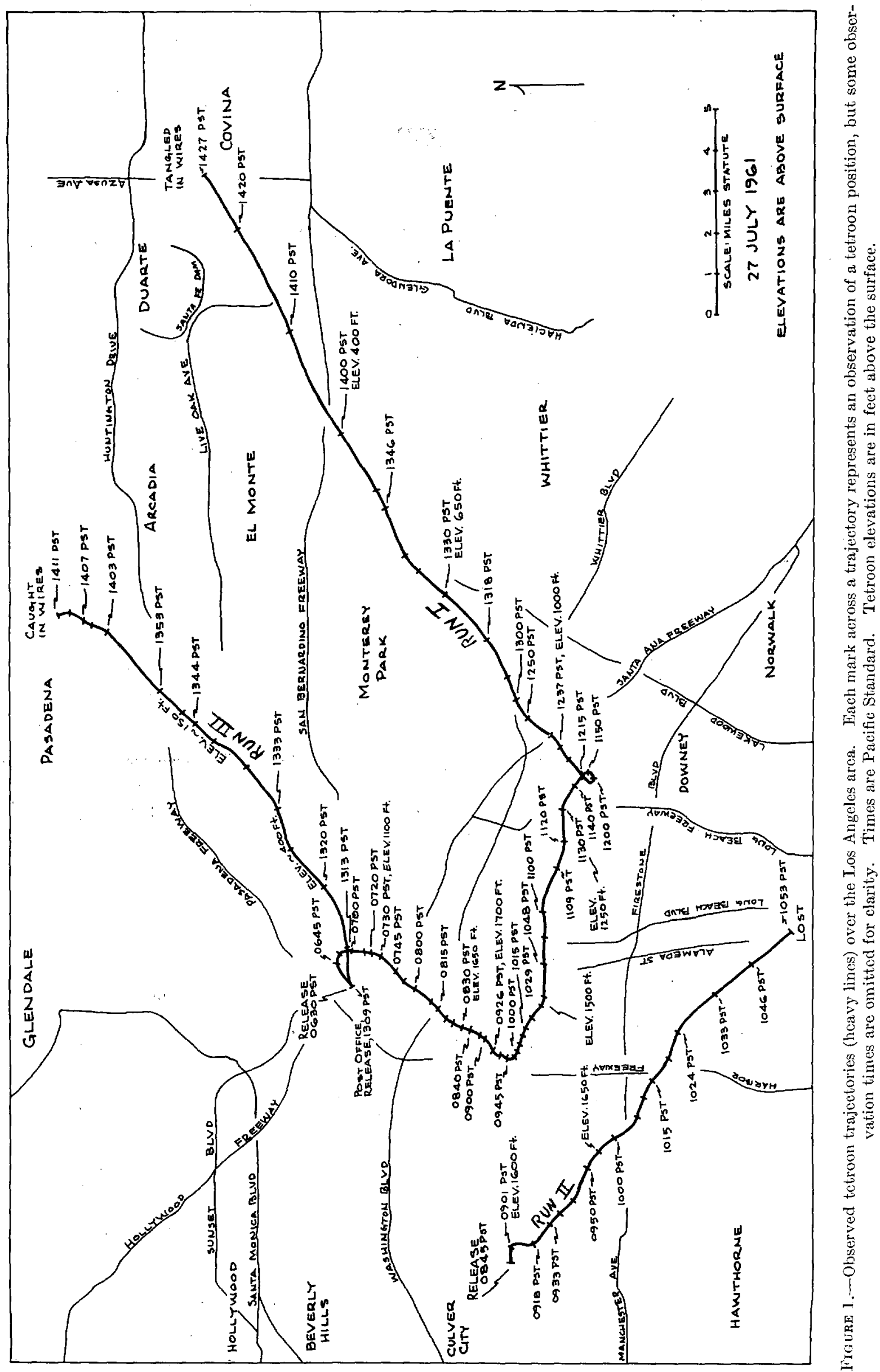
TABLE 1-Surface winds on July 27,1961 , at Los Angeles International Airport (LAX), top of the Los Angeles Federal Building (WBCO), Rivera (RVA), Compton (COM), and Pasadena (PAS). See figure 4 for station locations

\begin{tabular}{|c|c|c|c|c|c|}
\hline $\begin{array}{l}\text { Time } \\
\text { (IST) }\end{array}$ & LAX & WBCO* & $\mathrm{RVA}^{3}$ & COM 3 & PAS \\
\hline $\begin{array}{l}0500 \\
0600 \\
0700 \\
0800 \\
0900 \\
1000 \\
1100 \\
1200 \\
1300 \\
1400 \\
1500 \\
1600\end{array}$ & $\begin{array}{l}\text { W } 3 \\
\text { S } 3 \\
\text { WN W } 4 \\
\text { WSW } 3 \\
\text { WSW } 6 \\
\text { WSW } 6 \\
\text { W } 9 \\
\text { W } 8 \\
\text { WSW } 11 \\
\text { WSW } 15 \\
\text { WSW } 14 \\
\text { WSW } 15 \\
\end{array}$ & $\begin{array}{l}\text { W } 3 \\
\text { W } 4 \\
\text { W } 4 \\
54 \\
\text { S } 4 \\
\text { W } 6 \\
\text { W } 8 \\
\text { W } 9 \\
\text { W } 10 \\
\text { W } 13 \\
\text { W } 13 \\
\text { W } 11 \\
\end{array}$ & $\begin{array}{l}\text { ENE } 2 \\
\text { E } 2 \\
\text { E } 3 \\
\text { SW } 3 \\
\text { SE } 3 \\
\text { WSW } 4 \\
\text { SSW } 5 \\
\text { SW } 9 \\
\text { SW } 7 \\
\text { WSW } 9 \\
\text { WSW } 10 \\
\text { WSW } 8 . \\
\end{array}$ & $\begin{array}{l}\text { ESE } 1 \\
\text { NNE } 2 \\
\text { N } 3 \\
\text { E } 3 \\
\text { ESE } 2 \\
\text { SS W } 3 \ldots \\
\text { W } 9 \\
\text { W } 9 \\
\text { W } 11 \\
\text { W } 11 \\
\text { WN W } 12 \\
\text { W } 10\end{array}$ & $\begin{array}{l}\text { NNE } 2 . \\
\text { NW } 1 . \\
\text { E } 3 . \\
\text { SSE } 3 . \\
\text { S3 } \\
\text { SSW } 4 . \\
\text { SW 5. } \\
\text { SW 5. } \\
\text { SW 6. } \\
\text { SW 7. } \\
\text { WSW } 9 . \\
\text { WSW 7. }\end{array}$ \\
\hline
\end{tabular}

1 Observed on the hour. Speed in knots.

2 Prevaling direction to eight compass points during one hour beginning at hour indicated. Spced is total statute miles of wind passing station during the hour.

3 Prevailing direction during one hour centered on the hour indicated. Speed in miles per hour is average during the hour.

about 0600 PST but dissipated within two hours. The sea level isobars were roughly parallel to the southern California coast with thermal low pressure over the inland desert areas. At 1000 PST the pressure gradient was $4 \mathrm{mb}$. onshore in $200 \mathrm{n}$. mi. Surface wind data for the area are presented in table 1. Rivera, Compton, and Pasadena had downslope winds through 0700 PsT. Thereafter the westerly sea breeze and upslope winds prevailed, except at Compton where the sea breeze didn't clearly begin until about 1000 PST.

At Santa Monica (SMO in fig. 4) the 0300 PsT radiosonde observation showed an inversion based at $1020 \mathrm{ft}$. above mean sea level (m.s.l.) with a temperature increase of $8.0^{\circ} \mathrm{C}$. through $3840 \mathrm{ft}$. m.s.l. At 1500 PST the inversion base occurred at $890 \mathrm{ft}$. m.s.l., with a temperature increase of $12.1^{\circ} \mathrm{C}$. through $2390 \mathrm{ft}$. m.s.l. The winds aloft measured at Santa Monica are shown in table 2. According to these observations the sea breeze existed only in the lowest $1000 \mathrm{ft}$. at $0900 \mathrm{PsT}$, but increased in depth during the daytime to become dominant through at least the 2000- $\mathrm{ft}$. level by 1500 PST.

Tetroon trajectories are shown in figure 1. Each position fix is indicated by a perpendicular mark along the trajectory. For clarity some observation times are omitted. The terrain elevations are shown in figure 4. Descriptions of the various trajectories follow.

Run I (Release at 0630 PST).--This tetroon, one of a pair released simultaneously, was launched from the top of the Los Angeles Federal Building (labeled Post Office in fig. 1), $235 \mathrm{ft}$. above street level and $550 \mathrm{ft}$. m.s.l.

TABLE 2.- Winds (degrees and knots) at Santa Monica Airport on July $2 \%, 1961$

\begin{tabular}{r|c|c|c|c}
\hline \hline $\begin{array}{l}\text { Time } \\
\text { (PST) }\end{array}$ & Surface & $1000 \mathrm{ft}$. & $2000 \mathrm{ft}$. & $3000 \mathrm{ft}$. \\
\hline & & & & \\
\hline 0300 & Calm & $150-5$ & $250-8$ & $340-14$ \\
0900 & $210-6$ & $220-1$ & $290-3$ & $310-5$ \\
1500 & $260-16$ & $260-17$ & $260-13$ & $280-8$ \\
\hline
\end{tabular}

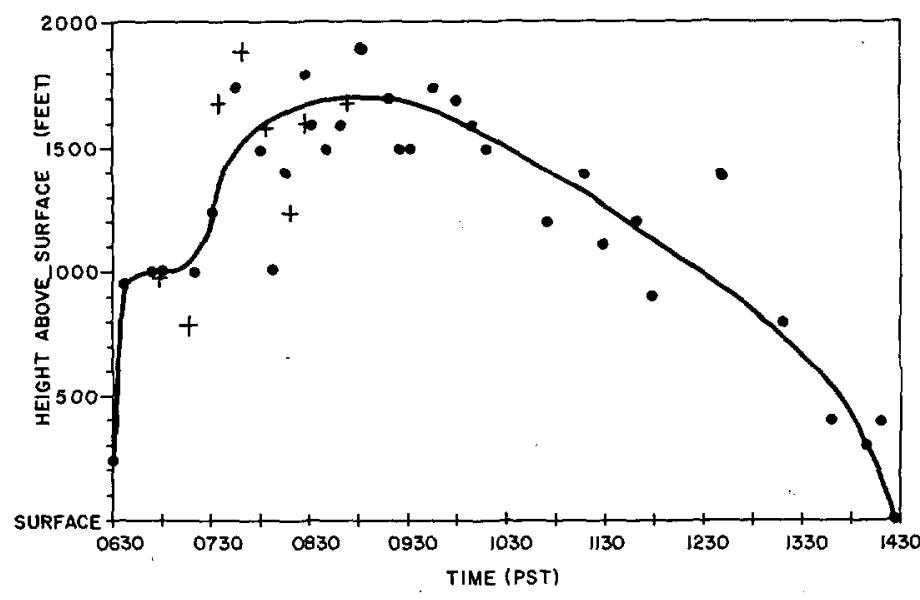

Figure 2.- Tetroon elevations above the ground for Run I (dots) and a companion tetroon (crosses). A smooth curve was fitted by eye through the dots. For terrain elevations see figure 4.

The monocular eyepiece method of tracking mentioned earlier, was used on this flight, and tetroon elevations as a function of time are shown in figure 2. Because of the inherent error of estimate in elevation height determinations, a smooth curve, fitted by eye, was drawn through the tetroon elevations in figure 2. Elevations on this curve are marked along Run $I$ in figure 1.

This trajectory exhibits the effects of three general air flows. The rapid veering indicated near the release point is attributed to the shear encountered as the tetroon ascended. The next portion of the trajectory, at tetroon elevations between 1100 and $1700 \mathrm{ft}$. (0730-0926 PST) shows a response to flow from the northeast. A rather abrupt shift to flow from the west-northwest occurred near 0945 PST. This appears to be the earliest manifestation of the sea breeze in Run I. The surface wind stations listed in table 1 generally showed a wind shift at 1000 PST, although surface wind directions were only in fair agreement with the tetroon movement. A transition between the early west-northwesterly sea breeze and the later southwesterly sea breeze resulted in a half-hour-long loop in the trajectory near noon. With the advent of the southwesterly sea breeze the tetroon was carried out to Covina, coming to earth there after a flight of almost $8 \mathrm{hr}$.

Run II (Release at 0845 PST).--The tetroon was sent aloft from an elevation of $450 \mathrm{ft}$. m.s.l. in the Baldwin Hills. Tetroon elevations were estimated from elevation angles and agreed well with the elevation of the other tetroon that was aloft at the same time. Some changes in the height of this tetroon were apparent, but after reaching flight altitude it was never estimated to be lower than 1000 $\mathrm{ft}$. above the surface. The direction of the Run II trajectory from 0918 to 1053 PST (fig. 1) is similar to that for Run I from 0945 to 1150 PsT, both being roughly from the northwest. Run II was terminated at 1053 PST because the tetroon was lost in haze. 


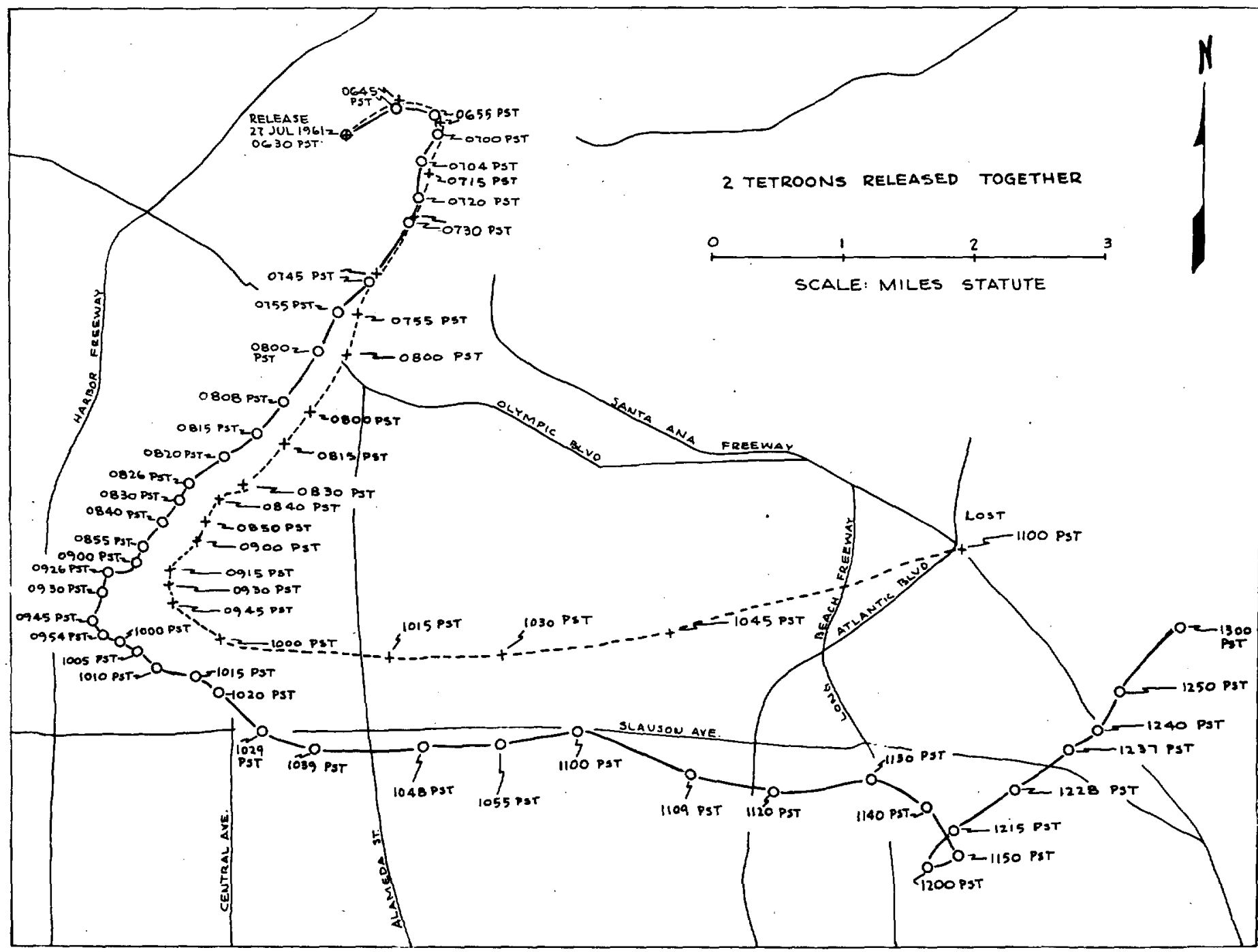

FIG URE 3.-Tetroon trajectories for the simultaneous release of two tetroons from the Federal Building. The trajectory indicated by circled positions is Run $I$ in figure 1. Positions of the companion tetroon are indicated by crosses.

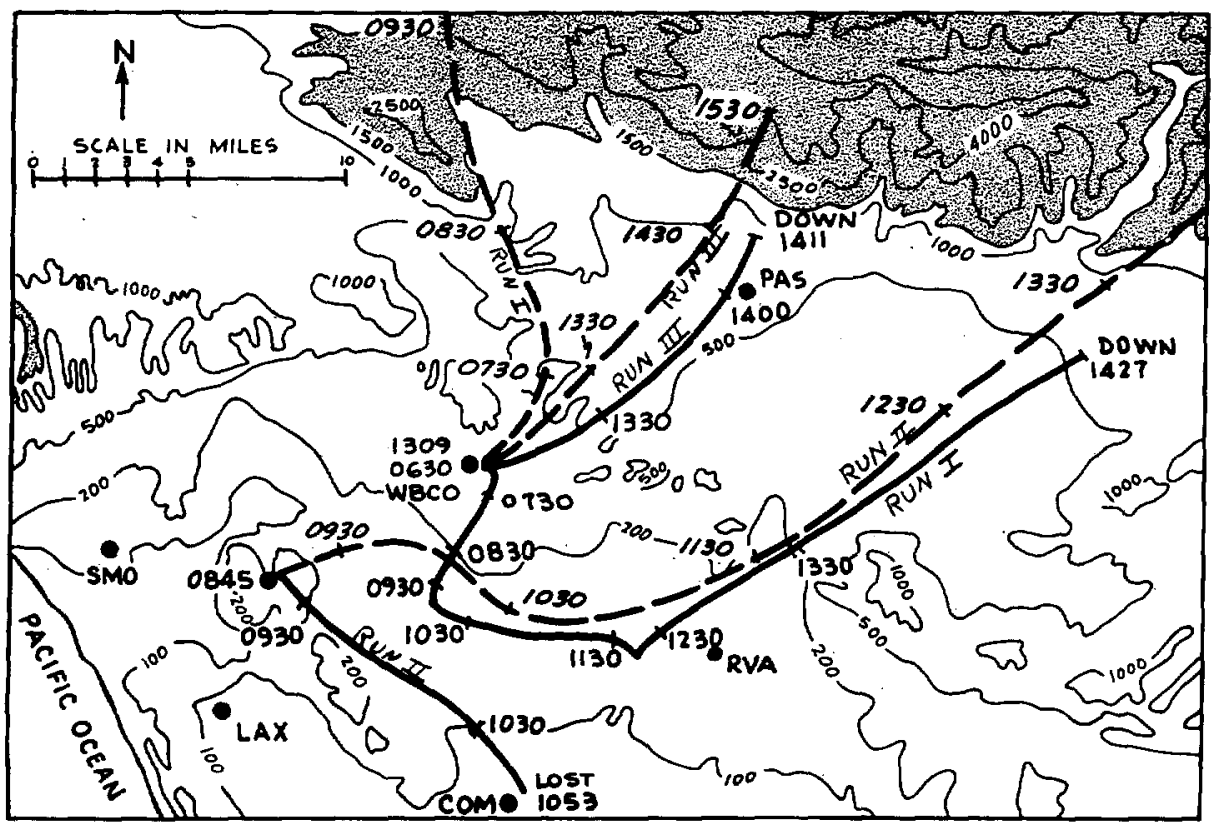

Figure 4.-Topography of the Los Angeles area; observed (heavy solid lines) and corresponding computed (heavy dashed lines) trajectories for Runs I, II, and III; and observation stations mentioned in the text. Numbers along trajectories are Pacific Standard time. 
Run III (Release at 1309 PST).--This release was from the top of the Federal Building. Initially. the tetroon was estimated to be $600 \mathrm{ft}$. above the surface, but this height decreased as the tetroon moved over higher terrain. These heights were in fair agreement with those at about corresponding times along the trajectory of Run I. The directions of movement of these two trajectories during corresponding periods were also in good agreement (fig. 1). Such flow toward the northeast in summer afternoons is typical of the surface flow over that part of Los Angeles.

\section{BEHAVIOR OF TWIN TETROONS}

Run I, mentioned above, actually involved the simultaneous release of two tetroons. The trajectory for Run I, shown in figure 1 , is pictured again on a larger scale in figure 3 , and indicated by the open-circle positions. The trajectory of the companion tetroon is represented by crosses. In addition to height calculations for Run I, some height data were also obtained for the companion tetroon from release time until $0850 \mathrm{PST}$. These heights are plotted as crosses in figure 2. During this early part of the flight the elevations of the two tetroons were generally about the same.

Of particular interest is the horizontal separation with time of the two tetroons. In figure 3 the companion tetroon was lost after 1100 PST. At 1300 PST it was found in the Santa Fe Dam basin (fig. 1) near the terminal point of Run I. This was $1.5 \mathrm{hr}$. before the tetroon of Run I had landed. As shown in figure 3, the two tetroons began separating rapidly after 1000 PST, just after the trajectories changed direction. It appears that the companion tetroon responded more readily to the incoming sea breeze from the west. This can be explained if we assume that the two tetroons were flying at different levels and that the sea breeze arrived at one level before affecting the other. According to the elevation estimates of these two tetroons near 1000 PST, the companion tetroon was flying at a lower level than the Run I tetroon. Therefore, the low-level intrusion of the sea breeze probably caught up the companion tetroon before it captured the Run I tetroon. There is no ready explanation, however, of why the tetroons should have been at different altitudes, since they were both initially ballasted to a free lift of $3.5 \mathrm{gm}$.

\section{COMPARISON OF COMPUTED AND OBSERVED TRAJECTORIES}

One of the purposes of this project was to compare the observed tetroon trajectories with corresponding trajectories computed from surface wind observations. These comparisons are shown in figure 4 . The surface trajectories were derived from a network of wind reporting stations maintained by the Los Angeles County Air Pollution Control District.

During the early part of Run I, when the tetroon was ascending to $1700 \mathrm{ft}$. above the surface, the corresponding surface trajectory was not at all in agreement. In this case the surface trajectory indicated southerly winds while the winds at tetroon level were from the northeast. Later in the day, when the tetroon was lower and apparently the sea breeze depth had increased, the computed surface trajectory was in good agreement with the tetroon trajectory, except the winds were stronger near the surface than aloft. For instance, in figure 4 after 1030 PST compare the computed surface trajectory of Run II with the tetroon trajectory of Run I.

For much of Run II the tetroon was more than $1500 \mathrm{ft}$. above the surface, and the computed and observed trajectories are at most only in fair agreement. In Run III the tetroon was never more than a few hundred feet above the surface, and the computed and observed trajectories are in quite good agreement.

From this experiment it appears that a valid comparison between trajectories based on surface wind reports and those derived from tetroon flights can be made only when the tetroons are kept below the inversion. Since in the present case it was planned to follow the movement of the polluted air, it must be admitted that a tetroon flying above the pollution-restraining inversion base did not successfully accomplish this part of its mission.

\section{AN OPERATIONAL PROBLEM}

Although the utilization of constant-volume balloons offers an opportunity to conduct various meteorological investigations at relatively low expense, potential users should be acquainted with an inherent difficulty. Figure 2 shows that after ascending to a flight level of approximately $1700 \mathrm{ft}$. above the surface (1900 ft. m.s.l.) at about 0900 PST, the Run I tetroon descended and reached the surface (500 ft. m.s.l.) at 1427 PsT. This behavior of a tetroon, sinking to lower levels as the day progresses, is attributed to the diurnal change in the density structure of the lower atmosphere. As pointed out earlier, the density of the tetroon system remains practically constant and the tetroon tends to float in the atmosphere along a surface with the same density as the balloon system. Therefore, as the air density decreases during the day, the tetroon floats at lower levels. From the equation of state the density of the atmosphere at the tetroon elevation (1900 fit. m.s.l.) at 0900 PST may be computed. As reported in the 0300 PST radiosonde observation at Santa Monica, the conditions at $1900 \mathrm{ft}$. m.s.l. were: temperature, $22.1^{\circ}$ C.; relative humidity, 65 percent; pressure $952 \mathrm{mb}$. (allowing for a $2-\mathrm{mb}$. diurnal rise from 0300 to 0930). For these values the resulting air density is $1.123 \mathrm{~kg} . \mathrm{m}^{3}$. Where the tetroon reached the ground (500 ft. m.s.1.) at 1427 PsT, the conditions were: temperature, $34.4^{\circ} \mathrm{C}$.; relative humidity, 50 percent (both estimated from nearby observations); and pressure $996 \mathrm{mb}$. (from the Federal Building station pressure at $512 \mathrm{ft}$. m.s.l. at noon, with allowance for a diurnal $1-\mathrm{mb}$. drop from noon to $1427 \mathrm{PST}$ ). For these values the resulting air density is $1.127 \mathrm{~kg} . / \mathrm{m}^{3}$. Considering the estimates 
involved, this value compares remarkably well with the earlier estimate of the density at $1900 \mathrm{ft} . \mathrm{m} . \mathrm{s} . \mathrm{l}$.

These changes of flight elevation with diurnal density changes result in a tetroon trajectory that does not really represent the air flow at a constant level. Adaptations of technique may be visualized that would overcome this problem by lessening the weight of the tetroon system during flight. However, this immediately adds to the cost and complexity of the operation. An alternative solution would be to release serial tetroons, but precise ballasting for preselected flight elevations is very difficult."

\section{REFERENCES}

1. J. G. Edinger, "A Study of Surface Air Flow in the Los Angeles Basin," Part I of "A Report on the Atmospheric Pollution Investigation in the Los Argeles Basin," University of California,
Departments of Engineering and Meteorology, Los Angeles, June 1948. (duplicated)

2. E. K. Kauper, R. G. Holmes, and A. G. Street, "The Los Angeles Basin Wind Flow Study," Los Angeles County Air Pollution Control District, Technical Paper No. 13, Los Angeles, undated.

3. M. Neiburger, "Tracer Tests of Trajectolies Computed from Observed Winds," Air Pollution Foundation Report No. 7, Los Angeles, Apr. 1955, 59 pp.

4. J. K. Angell and D. H. Pack, "Analysis of Some Preliminary Low-Level Constant Level Balloon (Tetroon) Flights," Monthly Weather Review, vol, 88, No. 7, July 1960, pp. 235 248.

5. J. K. Angell and D. H. Pack, "Estimation of Vertical Motions in Desert Terrain from Tetroon Flights," Monthly Weather Review, vol. 89, No. 8, Aug. 1961, pp. 273-283.

6. J. K. Angell and D. H. Pack, "Analysis of Low-Level Constant Volume Balloon (Tetroon) Flights from Wallops Island," Journal of the Atmospheric Sciences, vol. 19, No. 1, Jan. 1962, pp. $87-98$. 